\title{
ALGUMAS IMPLICAÇÕES METAÉTICAS ACERCA DA PERSPECTIVA DA SEGUNDA-PESSOA E DA FILOSOFIA MORAL KANTIANA
}

\author{
Emanuel Lanzini Stobbe ${ }^{1}$ \\ Universidade Estadual de Londrina \\ E-mail: e.1.stobbe@t-online.de
}

\section{RESUMO}

O presente artigo tem como objetivo apresentar e discutir uma resposta para a questão ética-metaética do respeito por outras pessoas, notadamente a da perspectiva da segunda-pessoa tratada por Stephen Darwall em "Respect and the Second-Person Standpoint" (2004). Darwall busca justificar seu ponto de vista partindo de quatro conceitos centrais: autoridade; exigência; razão de segunda-pessoa e responsabilização. Considerando sua teoria à luz da filosofia moral de Kant, Darwall pensa ter dado uma resposta satisfatoriamente suficiente à objeção de Iris Murdoch, segundo a qual Kant não justificaria o respeito por pessoas, mas apenas o respeito pela lei moral de se respeitar pessoas. Minha posição aqui é a de que a resposta de Darwall não é estritamente falando necessária para responder à objeção, uma vez que o próprio Kant pode ser interpretado de modo a respondê-la satisfatoriamente - sendo que se pode defender sua posição através de três principais argumentos: (1) que a objeção decorre de uma leitura errônea, tanto da filosofia, quanto dos propósitos kantianos; (2) que o respeito pela Lei Moral não desmerece o valor moral da ação correspondente; e (3) que o respeito por pessoas decorre indiretamente de uma extrapolação de nossa própria natureza racional, considerada pelo próprio Kant.

Palavras-chave: Pessoa; Respeito; Metaética.

\section{INTRODUÇÃO}

Por que, efetivamente, devemos - ou deveríamos - respeitar outras pessoas? $\mathrm{O}$ respeito por outros seres humanos é, por assim dizer, uma das grandes perguntas da filosofia moral ao longo da história da Filosofia - sendo também, certamente, uma das grandes questões da Metaética. Dentro da Metaética, uma resposta alternativa foi proposta por Stephen Darwall, tanto em seu artigo "Respect and the Second-Person Standpoint"2 (2004), quanto posteriormente em seu livro The Second-Person Standpoint: Morality, Respect, and Accountability (2006). Notadamente, sua resposta versa com a assim chamada "perspectiva da segunda pessoa", a qual, através da articulação de três conceitos centrais e um conceito relacionado, seria possível justificar

\footnotetext{
${ }^{1}$ Mestrando em Filosofia pela Universidade Estadual de Londrina (UEL), sob orientação do Prof. Dr. Aguinaldo Pavão. Bolsista de mestrado da Coordenação de Aperfeiçoamento de Pessoal de Nível Superior (CAPES). Graduado em Filosofia também pela UEL (2016).

${ }^{2}$ Sigo a tradução de Janyne Sattler em Metaética: algumas tendências (2013), "Respeito e a perspectiva da segunda-pessoa" (capítulo 7). Das obras de Kant, sigo a edição de Wilhelm Weischedel (Werke in zwölf Bänden. Frankfurt: Suhrkamp, 1991), referindo à paginação e abreviaturas da Akadiemieausgabe. As demais referências seguem a notação autor-data.
} 


\section{SEMINÁRIO DE PESQUISA EM CIÊNCIAS HUMANAS - SEPECH \\ Humanidades, Estado e desafios didático-científicos \\ Londrina, 27 a 29 de julho de 2016}

o respeito por outros seres humanos enquanto pessoas. Tais conceitos, assim, seriam: autoridade; exigência; razão de segunda-pessoa e responsabilização. De acordo com Darwall, uma exigência de respeito só seria válida partindo de uma autoridade que fosse reconhecida por outros também como válida para fazer uma tal exigência, de modo a gerar uma razão de segunda-pessoa - uma vez que se trataria de uma relação entre duas pessoas - para que tal exigência fosse cumprida; e isso levaria, por fim, a uma responsabilização para com uma tal pessoa ou comunidade (cf. DARWALL, 2013, p. 295-296).

A fim de examinar mais atentamente a posição de Darwall, bem como avaliar em que medida ela se faz relevante para responder o problema ético-metaético relacionado (notadamente, do respeito por outras pessoas), o presente artigo está dividido em três partes: em um primeiro momento, exponho os argumentos de Darwall, tal qual apresentados em seu artigo de 2004, dando enfoque para os quatro conceitos principais; em um segundo momento, trato da relação entre seu ponto de vista da segunda-pessoa e uma perspectiva kantiana (sendo Kant uma das principais influências para Darwall), contra a objeção de Iris Murdoch em "The Sublime and the Good" (1999), retomada por Darwall, de que a filosofia moral kantiana não justificaria o respeito por pessoas, mas sim meramente o respeito pela lei moral; e por fim, em um terceiro momento, apresento meu argumento contra uma relevância mais assertiva da posição da segunda-pessoa para propôr uma alternativa para a filosofia moral de Kant, na medida em que defendo que o próprio Kant pode ser interpretado de tal forma a responder satisfatoriamente à objeção de Murdoch.

\section{A PERSPECTIVA DA SEGUNDA-PESSOA}

Em "Respect and the Second-Person Standpoint" (2004), Stephen Darwall se volta majoritariamente para a questão do respeito por outros seres humanos, especialmente enquanto uma espécie de reivindicação que uma pessoa poderia fazer a outra - enquanto respeito por sua dignidade. Um ponto de partida apontado por ele, nesse sentido, seria considerar em que medida uma tal reivindicação poderia ser considerada como válida por uma outra pessoa (cf. DARWALL, 2013, p. 291-292). Assim, diz ele que: "a chave para respondermos a essas questões é a apreensão do caráter irredutível de segunda-pessoa tanto da nossa dignidade quanto do tipo de respeito que constitui a sua resposta mais apropriada" (DARWALL, 2013, p. 292). Tal caráter de segunda pessoa seria entendido na ideia de dignidade, enquanto autoridade para se fazer reivindicações uns dos outros enquanto agentes livres e racionais - de modo que a reciprocidade em questão seria um aspecto central.

Partindo disso, ele tira quatro ideias - três principais, e uma relacionada - por ele consideradas centrais para a justificação do respeito por outras pessoas a partir da perspectiva da segunda-pessoa: (1) a autoridade para fazer uma exigência de respeito; (2) a exigência de respeito, propriamente dita; (3) uma razão de segunda-pessoa gerada através da relação entre a autoridade e a exigência de respeito; e, por fim, (4) a responsabilização relacionada às três ideias anteriores. As quatro ideias estão, segundo Darwall, intrinsecamente relacionadas. Em linhas gerais, elas se dão na perspectiva da segunda-pessoa, uma vez que envolvem uma relação entre pessoas, na qual as duas 


\section{SEMINÁRIO DE PESQUISA EM CIÊNCIAS HUMANAS - SEPECH \\ Humanidades, Estado e desafios didático-científicos \\ Londrina, 27 a 29 de julho de 2016}

pessoas em questão se reconhecem mutuamente como tal, de modo a considerarem suas respectivas autoridades e exigências como válidas.

Darwall apresenta a relação entre os três primeiros conceitos da seguinte maneira:

Fazer uma reivindicação pressupõe sempre uma autoridade necessária para fazê-la, e assim a reivindicação devidamente autorizada cria uma razão distintiva para o seu cumprimento (uma razão de segundapessoa). A autoridade relevante consiste na posição para reivindicar ou exigir, a qual cria por sua vez uma razão desse tipo distinto. E uma razão de segunda-pessoa é de fato uma que deriva de uma reivindicação ou exigência impositiva (DARWALL, 2013, p. 296).

Nesse sentido, temos os conceitos de reivindicação e autoridade como diretamente relacionados: a reivindicação pressupõe a autoridade, e a autoridade consiste na posição de reivindicar. A razão de segunda-pessoa, por sua vez, é derivada da reivindicação - e consequentemente da autoridade. Assim, uma tal razão é gerada, na medida em que a outra pessoa (na relação entre pessoa e pessoa) admite a autoridade enquanto posição para se fazer reivindicações - do outro como válida, de modo a considerar também a própria reivindicação como válida.

A razão de segunda-pessoa é, então, uma razão relativa-ao-agente - e não meramente neutra-ao-agente: "já que as razões de segunda-pessoa derivam sempre das relações dos agentes uns com os outros, elas são invariavelmente, de um modo ou de outro, relativas-ao-agente; e aplicam-se a nós a partir da rede dessas relações" (DARWALL, 2013, p. 298). Isso se dá por conta de que a relação na qual ela se dá é uma relação entre duas pessoas, sendo endereçada justamente à outra pessoa enquanto pessoa. Essa razão é aceita enquanto razoável somente se a autoridade por ela pressuposta for aceita como válida (de modo que o próprio requerimento também seja assim aceito). Caso contrário, se a autoridade não for entendida como válida, o requerimento também não é considerado válido - de modo que uma razão de segundapessoa não é daí derivada.

Dos três conceitos anteriores, Darwall tira o conceito de responsabilização:

A autoridade de se exigir alguma coisa implica não apenas uma razão para que o endereçado venha a cumpri-la, mas também que ele possa ser responsabilizável por assim fazê-lo. Inversamente, a responsabilização implica a autoridade para responsabilizar, a qual implica, por sua vez, a autoridade para reivindicar ou exigir, que é a posição a partir da qual as razões de segunda-pessoa são endereçadas (DARWALL, 2013, p. 296).

Deste modo, temos que os quatro conceitos - tanto os três primeiros, quanto o conceito relacionado - estão interligados, implicando-se mutuamente: o requerimento de respeito pressupõe autoridade; ambos implicam uma razão de segunda-pessoa (entre duas pessoas, relativa-ao-agente); e por fim essa relação gera responsabilização. 


\title{
XI SEMINÁRIO DE PESQUISA EM CIÊNCIAS HUMANAS - SEPECH \\ Humanidades, Estado e desafios didático-científicos \\ Londrina, 27 a 29 de julho de 2016
}

\section{RESPEITO NA PERSPECTIVA DA SEGUNDA-PESSOA E A OBJEÇÃO DE MURDOCH}

Partindo dessas quatro ideias centrais, Darwall tira que o respeito seria, portanto, um tipo de admissão de autoridade. Ele distingue dois tipos de respeito em seu artigo "Two Kinds of Respect" (1977): o respeito enquanto apreço e o respeito enquanto reconhecimento. Enquanto o primeiro estaria relacionado à estima moral (através da qual se reconhece alguém enquanto pessoa, como agente moral), o segundo estaria relacionado à dignidade, e à autoridade propriamente dita dessa pessoa - tendo tanto a dignidade quanto a autoridade como objeto (cf. DARWALL, 2013, p. 305). Nesse sentido, o respeito enquanto reconhecimento seria necessário para se justificar os quatro conceitos anteriores, uma vez que remete à autoridade para endereçar razões de segunda-pessoa - autoridade esta que possibilita fazer reivindicações, gerando efetivamente uma razão de segunda-pessoa para que estas sejam cumpridas (e consequentemente uma responsabilização relacionada).

Darwall lança mão do respeito enquanto reconhecimento para afirmar que "a única maneira de uma posição de segunda-pessoa poder ser justificada é a partir de uma pespectiva de segunda-pessoa" (DARWALL, 2013, p. 308). Isso se deve justamente porque, enquanto remetendo à autoridade, a dignidade (objeto do respeito enquanto reconhecimento) envolve uma autoridade que é necessariamente de segunda-pessoa.

Diz ele:

\begin{abstract}
Ser uma pessoa é justamente possuir a autoridade para endereçar exigências enquanto pessoa para outras pessoas, e ser também por elas endereçada no contexto de uma comunidade de iguais mutuamente responsabilizáveis. Creio que daí decorre que nós respeitamos alguém enquanto pessoa ao lhe concedermos essa autoridade de segunda-pessoa, ou seja, ao nos relacionarmos adequadamente com ele enquanto pessoa, em caráter de segunda pessoa (DARWALL, 2013, p. 309).
\end{abstract}

Ao chegar nesse ponto, Darwall acredita poder endereçar à objeção de Iris Murdoch, ao relacionar sua perspectiva da segunda-pessoa à filosofia moral de Kant. Murdoch, em seu artigo "The Sublime and the Good" (1999), criticara a filosofia moral kantiana, no sentido de que a ética de Kant não dizia para "respeitar [...] indivíduos, mas para respeitar a razão universal em seu seio" (MURDUCH, 1999, p. 215). Nesse sentido, temos o seguinte problema, partindo da objeção de Mudoch: a filosofia moral de Kant não nos diria para respeitar pessoas, mas sim para respeitar tão somente a lei moral - e isso seria não apenas estranho (do ponto de vista de uma espécie de formalismo vazio), mas também seria uma falha da filosofia moral kantiana (na medida em que não responde por que respeitar pessoas, propriamente ditas).

Para responder tal objeção - tanto para oferecer uma solução kantiana para o problema, quanto para impedir sua própria perspectiva da segunda-pessoa de cair no mesmo suposto erro - Darwall apresenta uma espécie de interpretação kantiana de sua própria perspectiva da segunda-pessoa. Segundo ele, certamente seria um "um grave defeito da posição de Kant" (DARWALL, 2013, p. 310) se Kant tivesse, de fato, justificado tão somente o respeito pela lei (que Murdoch chama de "razão universal") e não o respeito por outras pessoas. Entretanto, de acordo com Darwall, esse não seria o 


\section{SEMINÁRIO DE PESQUISA EM CIÊNCIAS HUMANAS - SEPECH \\ Humanidades, Estado e desafios didático-científicos \\ Londrina, 27 a 29 de julho de 2016}

caso: provas de que Kant não teria um tal objetivo (de justificar apenas o respeito pela lei) poderiam ser encontradas em passagens de Kritik der praktischen Vernunft (1788) e Die Metaphysik der Sitten, especificamente em Tugendlehre (1797) (cf. KpV, AA 05: 73-74, 199-200; MS, AA 06: 402, 449, 462, 579).

As passagens em questão se referem, em linhas gerais, à distinção entre reverentia e observantia (cf. MS, AA 06: 402, 449) - sendo a primeira um sentimento de respeito, e a segunda o respeito no sentido prático - partindo do contraste entre o respeito por pessoas e da arrogância, no sentido de uma presunção de se estar acima da lei moral. Tal presunção - enquanto "fantasia a respeito do status de segunda-pessoa" (DARWALL, 2013, p. 311) - deveria ser derrubada pela própria lei moral, na medida em que todas as pessoas seriam iguais frente à lei moral (cf. KpV, AA 05: 73, 199).

Tanto em KpV quanto em MS, ao se voltar para a questão do respeito, afirma Darwall que Kant teria tratado do respeito em termos de segunda-pessoa, na medida em que se reconhece e reivindica uma autoridade para se fazer exigências (cf. DARWALL, 2013, p. 310). Diz ele:

Tal como eu interpreto, a ideia de Kant nessas passagens [KpV, AA 05: 73-74, 199-200; MS, AA 06: 402, 449, 462, 579] não é simplesmente a de que há um valor representado nas pessoas, ou normas que governam a nossa conduta para com elas, que deve ser respeitado, mas a de que as pessoas elas mesmas possuem autoridade para fazer exigências umas às outras enquanto pessoas iguais, livres e racionais, e que ao respeitarmos essa autoridade nós as estamos respeitando (DARWALL, 2013, p. 310).

Darwall, nesse sentido, busca interpretar a filosofia moral kantiana de tal forma que seja possível, ao mesmo tempo, defender a possibilidade do respeito por pessoas elas mesmas e ainda assim não precisar de um valor em si dessas pessoas. $\mathrm{O}$ respeito por pessoas seria devido, assim, à autoridade destas para fazer exigências enquanto pessoas iguais, livres e racionais; e tal autoridade seria acessível através da justificação pelos quatro conceitos principais da perspectiva da segunda-pessoa.

Deste modo, seria possível, de acordo com ele, conciliar sua posição da segundapessoa com a noção kantiana de um "reino dos fins" [Reich der Zwecke $]^{3}$. Para tanto, Darwall parte da noção de "presunção", segundo a qual alguém se consideraria como tendo um valor independente da lei moral. Por sua vez, a própria lei moral se encarregaria de derrubar qualquer tipo de presunção (ou arrogância), ao declarar como nulas todas as suas reivindicações, uma vez que tal presunção desconsidera a igual dignidade das pessoas - enquanto iguais, livres e racionais. Acerca disso, diz ele:

A lei moral substitui o fantasioso despotismo da presunção pela igual dignidade das pessoas. No lugar de uma imaginada hierarquia, ela nos oferece o reino dos fins, a ideia segundo a qual todas as pessoas possuem a mesma autoridade para fazer exigências umas das outras enquanto membros de uma comunidade de iguais mutuamente responsabilizáveis (DARWALL, 2013, p. 313, grifo meu).

\footnotetext{
${ }^{3}$ Darwall menciona o artigo de Christine Korsgaard, "Creating the Kingdom of Ends" (1996). Apesar de se tratar de um artigo extremamente interessante, me limitarei aqui em apenas mencioná-lo também.
} 


\section{SEMINÁRIO DE PESQUISA EM CIÊNCIAS HUMANAS - SEPECH \\ Humanidades, Estado e desafios didático-científicos \\ Londrina, 27 a 29 de julho de 2016}

O reino dos fins, assim, traz consigo a noção de pessoas iguais, livres e racionais que tratamos antes; partindo a terminologia utilizada por Darwall, ele afirma ainda:

Reconhecer plenamente a autoridade igual de outra pessoa para fazer exigências enquanto pessoa é considerar a si mesmo como responsabilizável perante o outro em também cumprí-las. É colocar a si mesmo em uma relação de segunda-pessoa com o outro em lugar de simplesmente levar em conta um fato, norma ou valor qualquer que o envolva (DARWALL, 2013, p. 313, grifo meu).

Darwall também trata, na sequência de sua argumentação, da distinção kantiana entre deveres de amor e deveres de respeito (cf. MS, AA 06: 448, 462-464, 568, 579, 581). Em Kant: "todo ser humano possui uma revindicação legítima de respeito por parte de seus companheiros humanos e é reciprocamente obrigado a respeitar a todos os outros" (MS, AA 06: 462, tradução minha). De tal distinção e passagens relacionadas, ele tira que:

[...] o dever de respeito compreende qualquer dever específico cujo cumprimento as pessoas têm a autoridade para exigir. E respeitar os outros enquanto pessoas iguais requer requer de nós que possamos cumprir tais deveres. Mas requer de nós, além disso, que venhamos a reconhecer a 'legítima reivindicação' dos outros para que assim o façamos, e isso nós só podemos de fato fazer ao reconhecer a sua autoridade para reivindicá-lo ou exigi-lo. É isso o que traz a responsabilização e a segunda-pessoa à tona" (DARWALL, 2013, p. $314)$.

Nesse sentido, para Darwall, Kant se compromete de que a ideia de dignidade das pessoas inclui uma autoridade de segunda-pessoa com relação às exigências de cumprimento dos deveres de respeito. Assim, seria insuficiente cumprir as exigências meramente por conta de estas serem requeridas pelo dever (da lei, propriamente dita), de tal modo que a perspectiva da segunda-pessoa forneceria uma saída para como respeitar pessoas através de relações, justamente, de segunda-pessoa (entre pessoas, enquanto iguais, livres e racionais - mutuamente responsabilizáveis, membros de um reino dos fins).

Ao afirmar que o colocar-se em uma relação de segunda-pessoa com o outro estaria, de certo modo, além de se levar em conta um fato, norma ou valor que o envolva, Darwall busca dar uma resposta direta à objeção de Murdoch. Para ele, não bastaria - em Kant, de acordo com sua interpretação - justificar o respeito pela lei que, no caso, seria a norma, mas muito mais justificar a relação de segunda-pessoa, na medida em que esta se dá através de um reino dos fins - no qual todos são considerados como pessoas iguais, livres e racionais. Deste modo, retomando o que fora dito anteriormente, temos que, a partir de uma relação de segunda-pessoa, a própria pessoa do outro estaria sendo respeitada - pois a validade de sua autoridade e reivindicação é garantida por meio da própria relação (através da razão de segunda-pessoa e consequente responsabilização).

\footnotetext{
4 „Ein jeder Mensch hat rechtmäßigen Anspruch auf Achtung von seinen Nebenmenschen, und wechselseitig ist er dazu auch gegen jeden anderen verbunden " (MS, AA 06: 462).
} 


\section{SEMINÁRIO DE PESQUISA EM CIÊNCIAS HUMANAS - SEPECH \\ Humanidades, Estado e desafios didático-científicos \\ Londrina, 27 a 29 de julho de 2016}

Em linhas gerais, é justamente essa a resposta de Darwall: por mais que, de certo modo, comentando a filosofia moral de Kant, ele aponta tanto para uma saída para esta contra a objeção de Murdoch (através da perspectiva da segunda-pessoa), quanto para sua própria perspectiva de segunda-pessoa enquanto justificação para o respeito por outras pessoas - uma vez que se estaria respeitando pessoas, propriamente ditas, por meio das relações de segunda-pessoa. Sobre o segundo ponto, sua perspectiva parece se sustentar por meio principalmente de seus quatro conceitos principais - de modo a parecer uma justificação interessantemente válida para o problema filosófico do respeito por outras pessoas. Entretanto, sobre o primeiro ponto, de que sua própria perspectiva garante uma saída para a filosofia moral kantiana, há ainda um ponto central a se discutir: o de que a perspectiva de segunda-pessoa é desnecessária para a resposta kantiana - e isso, em grande medida, porque a própria objeção (e não a filosofia moral kantiana) tem problemas quanto à formulação e relevância. Trataremos disso já na sequência.

\section{UMA POSSÍVEL RESPOSTA KANTIANA ACERCA DO RESPEITO POR PESSOAS E PELA LEI MORAL}

Retomemos a objeção de Murdoch: ela afirma que a filosofia moral de Kant não teria se preocupado com justificar o porquê de se "respeitar [...] indivíduos, mas [...] respeitar a razão universal em seu seio" (MURDUCH, 1999, p. 215). Isso, também na interpretação de Darwall da objeção, significaria que seria um "um grave defeito da posição de Kant" (DARWALL, 2013, p. 310) se ele tivesse buscado justificar o respeito pelo requerimento - isto é, o respeito pela própria lei moral - e não o respeito por pessoas, propriamente ditas. Pois bem, por mais que Darwall tenha se esforçado em tentar mostrar que esse não seria o caso nem mesmo em Kant, ao considerar passagens de outras obras, e por mais que sua resposta seja interessante (especialmente no que cabe relacionar sua perspectiva da segunda-pessoa à filosofia moral kantiana), afirmo que a resposta de Darwall é, já em um ponto de partida, desnecessária. Isso não se dá por demérito nem de sua perspectiva, nem de sua relação com a filosofia moral de Kant; mas sim por conta da má leitura que a própria objeção supõe da ética kantiana.

Ao que parece, a intenção de Murdoch seria apontar para o fato de que, ao se buscar justificar respeito por pessoas, as próprias pessoas seriam variantes essenciais à equação, por assim dizer - isto é, deveria ser possível tomá-las em sua condição de fim em si mesmo e dotadas de um valor absoluto inerente (exterior ao próprio agente moral). Entretanto, tal leitura apresenta diversos problemas. Em primeiro lugar, a objeção não compreende bem nem o projeto kantiano em sua filosofia moral (com maior destaque a GMS, nesse sentido), nem a filosofia kantiana como um todo sistemático (acerca da busca por leis universais e necessárias, bem como de não ser possível acessar um valor externo de outra pessoa, uma vez que este não poderia ser dado na sensibilidade). Em segundo lugar, o "seguir regras" (no caso, o "seguir a lei moral") não seria demérito nem para a filosofia moral kantiana (uma vez que busca apontar para o rumo necessário e universal de ações, e não meramente se preocupar com manter a justificação do respeito por outras pessoas em um valor externo, próprio dessas pessoas - até porque isso não seria possível), e nem para o agente moral humano (uma vez que este só poderia agir de tal modo a respeitar a lei moral como curso correto de 


\section{SEMINÁRIO DE PESQUISA EM CIÊNCIAS HUMANAS - SEPECH \\ Humanidades, Estado e desafios didático-científicos \\ Londrina, 27 a 29 de julho de 2016}

ação, sendo que não há outra alternativa, já que valores externos são inacessíveis). Em terceiro lugar, o respeito por outras pessoas seria decorrente do respeito à própria lei, através de uma extrapolação da condição de fim em si mesmo da própria natureza racional do agente (observando em outros objetos morais, por assim dizer, características nas quais identifica a sua própria condição enquanto fim em si mesmo, podendo extrapolar a condição da sua própria natureza racional enquanto autônoma, autolegisladora, para esses demais objetos, que recebem o status de pessoas - a serem respeitadas em decorrência de tal extrapolação).

Em primeiro lugar, afirmo que uma tal objeção não compreende bem nem o projeto kantiano, nem sua filosofia como um todo sistemático (ou pelo menos sua filosofia crítica). Do primeiro, o projeto kantiano, destaca-se a condição de leis universais e necessárias, à procura das quais Kant se lança ao longo de seus textos sobre filosofia moral (dos quais destaco de modo especial, certamente, GMS). Do segundo, sua filosofia crítica, já da distinção entre fenômeno e noúmeno em $\mathrm{KrV}$ se é possível partir para concluir que não é possível conhecer outros seres humanos como "coisa em si" - de modo que ter contato com um valor externo de outros seres humanos, sendo que tal valor é o que deveria ser respeitado, seria impossível (justamente por conta de nossa natureza enquanto seres racionais sensíveis, que não conseguem conhecer a coisa em si). Por si só, isso já daria conta de refutar um primeiro aspecto da objeção acima considerada, a saber, de que agir respeitando valores externos (leia-se, conhecendo tais valores primeiros, para então conseguir respeitá-los enquanto tais) deveria garantir o valor moral para a ação. Se esse não pode ser o caso - e, como afirmo, junto à minha interpretação de Kant, não pode - então não seria possível agir respeitando tais valores externos. O que sobra, assim, são duas alternativas: ou se tira que o valor moral das ações é justificado através do respeito à Lei Moral enquanto regra, ou não se tira valor moral algum (uma vez que o objeto externo de respeito estaria sempre fora de alcance).

Por mais que o "seguir regras" pudesse beirar mesmo ao pejorativo para compor a objeção, esse não precisa ser o caso; mesmo porque, como vimos, a outra alternativa não é viável (antes uma justificação menos esperável, mas eventualmente aceitável, do que nenhuma justificação). E aqui chegamos no segundo ponto do argumento contra a objeção: "seguir regras", ou seguir o Imperativo Categórico, enquanto justificação para o respeito por outros seres humanos, não é demérito algum - nem para a filosofia moral kantiana, nem para o valor do agente moral e suas respectivas ações. Em primeiro lugar, não é desvantagem para a filosofia moral kantiana, justamente porque ela se propõe a apontar para um curso de ação que seja universal e necessário (como vimos no ponto anterior do argumento); tal curso de ação, de se agir seguindo a Lei Moral, é universal e necessário - isto é, se respeitarmos a lei que a nossa própria razão nos dá, estaremos agindo universal e necessariamente de modo correto (moralmente bom). Em segundo lugar, também não é demérito para o agente moral e suas ações, porque fatidicamente ele não pode acessar o valor de outros seres humanos, de modo a precisar se contentar com o "seguir a regra" como justificação para o respeito de outros seres humanos. Não é demérito, justamente porque ele não pode ter outro tipo de conhecimento moral, por assim dizer. Assim, é melhor que ele aja seguindo a lei da sua própria razão, que de certa maneira extrapola sua própria condição de fim em si mesmo também para outros supostos seres humanos (nos quais o agente reconhece a própria humanidade, no sentido kantiano de natureza racional, que ele mesmo detém) - de um modo que a ele é garantido, pela própria razão, ser universal e necessário, do que ter o valor moral de 


\section{SEMINÁRIO DE PESQUISA EM CIÊNCIAS HUMANAS - SEPECH \\ Humanidades, Estado e desafios didático-científicos \\ Londrina, 27 a 29 de julho de 2016}

suas ações sempre desconsiderado por não ter acesso ao valor dos outros seres que deveria respeitar.

Chegamos agora, por fim, à terceira etapa do argumento. Meu ponto, basicamente, é de que não há problema em justificar o respeito por outros seres humanos através do nosso próprio "seguir regras" - porque isso faz parte de algo como uma extrapolação de nossa própria natureza racional no sentido moral. A fim de justificar esse ponto, considero o seguinte: o respeito por outros seres humanos se dá através de uma extrapolação de nossa própria condição enquanto fins em si mesmos portanto, enquanto autônomos. Tal extrapolação se dá na medida em que a nossa própria razão dá a si mesma a lei segundo a qual se deve seguir (a autonomia, como fundamento da moralidade); essa lei é a própria Lei Moral, em nós expressa na forma do Imperativo Categórico; o Imperativo Categórico, especialmente na Fórmula da Humanidade, comanda o respeito a outros seres racionais sensíveis (no caso, seres humanos), enquanto fins em si mesmos, isto é, dotados de valor absoluto - mesmo sem que tenhamos conhecimento de tais valores propriamente ditos (cf. GMS, AA 04: 426429). Para tanto, nossa própria razão extrapola sua própria condição de fim em si mesmo, e de dotada de valor absoluto (que Kant busca justificar na terceira seção de GMS através do argumento de que somos seres racionais sensíveis com dupla cidadania nos mundos sensível e inteligível) - não se precisa conhecer o valor do outro propriamente dito, mas apenas "reconhecê-lo", por assim dizer". Ora, consideremos o seguinte: se não é possível conhecer o valor de outros seres humanos propriamente ditos, a única fonte de justificação para o respeito por esses outros seria exatamente a própria lei, garantida pela nossa própria racionalidade; o valor desses outros seria daí inferido, por mais que não possa ser conhecido - e isso se dá através de uma extrapolação de nossa própria natureza racional (e consequente dupla-cidadania nos mundos sensível e inteligível, tal qual Kant trata na justificação do Imperativo Categórico na terceiro seção de GMS).

Imagino ter conseguido, através desse três pontos centrais de meu argumento, apresentar uma refutação consistente da objeção de Murdoch - particularmente se a considerarmos como uma objeção à justificação do respeito por outros seres humanos na filosofia moral kantiana como dada à parte de um "seguir regras" - tanto se considerarmos a filosofia e o projeto kantianos, quanto a viabilidade do próprio "seguir regras" como fundamento para o respeito de outros. Nesse sentido, considerando que não há problema em se assumir que a justificação pelo respeito por outros seres humanos se dê através do "seguir regras" - enquanto "seguir a lei moral" - não há necessidaade de lançar mão da perspectiva da segunda-pessoa elaborada por Darwall, uma vez que ainda se pode dizer que o respeito por pessoas é decorrente da justificação pelo respeito da própria lei, por mais que tal respeito por pessoas se dê através de uma extrapolação de nossa própria condição enquanto seres autônomos, autolegisladores, e, assim, enquanto fim em si mesmo. Ainda assim, pode-se dizer que a interpretação de Darwall da filosofia moral de Kant, não enquanto comentário com relação à objeção de Murdoch, mas sim enquanto articulação de seus próprios conceitos, tem diversos méritos, especificamente com relação a oferecer uma alternativa metaética para

\footnotetext{
${ }^{5}$ E aqui temos uma aproximação interessante com o respeito enquanto reconhecimento em Darwall - por mais que não precisando lançar mão de sua perspectiva de segunda-pessoa como um todo para resolver a questão.
} 


\section{SEMINÁRIO DE PESQUISA EM CIÊNCIAS HUMANAS - SEPECH \\ Humanidades, Estado e desafios didático-científicos \\ Londrina, 27 a 29 de julho de 2016}

responder à questão do respeito por outros seres humanos enquanto pessoas, especialmente ao tratar do conceito propriamente dito de pessoa e sua relação com $o$ reino dos fins.

\section{CONSIDERAÇÕES FINAIS}

Por fim, apresento uma breve conclusão: a posição de segunda-pessoa fornecida por Darwall é interessante, na medida em que trata do problema do respeito por outros seres humanos através de uma perspectiva metaética. Os quatro conceitos principais apresentados por Darwall - a saber, autoridade para fazer exigências, reivindicação, razão de segunda-pessoa e responsabilização - parecem ser, até onde me permito afirmar, tratados de um ponto de vista original. Além disso, sua posição é intrigante, por conta de se apresentar como coerente: assumamos os quatro conceitos, e do ciclo resultante entre esses temos uma justificação razoável para o requerimento de respeito. Entretanto, como apontei na seção final, a posição de Darwall é desnecessária no que se refere a oferecer uma resposta à objeção de Iris Murdoch, considerando a filosofia moral de Kant; isso se dá, como vimos, na medida em que o próprio Kant oferece ferramentas conceituais para não apenas responder à objeção (como a extrapolação de nossa própria condição enquanto fim em si mesmo, que decorre do que Kant trata principalmente em GMS), como também desqualificá-la (uma vez que parece mais resultado de uma leitura equivocada do que um problema para a ética kantiana propriamente dita).

\section{REFERÊNCIAS BIBLIOGRÁFICAS}

DARWALL, Stephen. "Respeito e a perspectiva de segunda-pessoa". In: Metaética: algumas tendências. Organização de Darlei Dall'Agnol, tradução de Janyne Sattler. Florianópolis: Editora da UFSC, 2013.

The Second-Person Standpoint: Morality, Respect, and Accountability. Harvard: Harvard University Press, 2006.

. “Two Kinds of Respect”. In: Ethics, Vol. 88, No. 1 (Oct., 1977), 36-49.

KANT, Immanuel. Werke in zwölf Bänden. Herausgegeben von Wilhelm Weischedel. Frankfurt: Suhrkamp, 1991.

KORSGAARD, Christine M. Creating the Kingdom of Ends. Cambridge: Cambridge University Press, 1996.

MURDOCH, Iris. "The Sublime and the Good". In: Existentialists and Mystics, ed. Peter Conrad. New York: Penguin Books, 1999. 